\title{
Waste Simplification for Warehouse Using Boolean Logic
}

\author{
M. S. Sarifudin, *M. A. Mansor and W. Safiei \\ Faculty of Engineering Technology, University Malaysia Pahang, 26300, Kuantan, Pahang, \\ Malaysia \\ *Email : ariffin@ump.edu.my
}

\begin{abstract}
Warehouse accumulates non-value added or wastes activities consist of inventory, waiting and transportation. The warehouse is a must to prevent any unforeseen events causing failures to implement the Just-In-Time concept. However, the existence of the warehouse will increase the operation expenditure and can lead to the profit losses. Therefore, the manufacturer needs to identify and eliminate the wastes to reduce the consumption of the resources and keep minimum requirement of the activities such as inventory, waiting and transportation in the warehouse. Value Stream Mapping is one of the Lean tools as an approach to eliminate the non-value added or wastes. This tool visualizes the information and material flow of the manufacturing activities. The development of a model based from Value Stream Mapping determined the current state of the wastes existed in the warehouse activities. The model is used to identify and eliminate the waste in the warehouse. From the information flow, the optimum combination of the wastes was determined through Boolean concept. The wastes are simplified and combined by passing through the Boolean operators consist of AND Gate and OR Gate. The expected outcome of this paper is to propose a conceptual model of new value stream mapping to identify and eliminate the waste in the warehouse. From the removal of wastes, the profit can be increased by reduction of the operation expenditure of the manufacturer.
\end{abstract}

Indexed Terms- Warehouse, Waste, Lean Manufacturing, Value Stream Mapping, Boolean

\section{INTRODUCTION}

The warehouse commonly as the interchange place between supplier, production lines and customer [1] and it is an important unit for the company within the logistics system. The activities such as storing the products in the form of unprocessed material, finished product during or between points of origin and also points of consumption are common in the warehouse. Besides, buffering and storage is the main function of the term 'warehouse' [2]. In the typical supply chain network, the warehouse functions to transform the raw material into the final products and sequentially processed at multiple locations [3]. The common activities that existed in the warehouse consist of inventory, waiting and transportation of materials. According to Toyota Production System (TPS), the activities such as inventory, waiting, transportation, motion, overprocessing, over-production and defect were classified as the wastes during the development of TPS [4]. In the lean manufacturing, the main characteristic of the waste is not given additional value to finished product based on Tapping [5]. Warehousing and inventory as the main contributor for the large part of the total cost of logistic and Ohno [6] believed that the wastes contributed up to $95 \%$ of all cost in non-Lean Manufacturing environments. One of the goals in an implementation of Lean Manufacturing concept is to eliminate the waste. Waste elimination is one of an effective way to reduce the cost of production and contribute to the high profit of most companies. As an approach, Value Stream Mapping is applied in the companies to achieve the waste eliminations.

The general concept of Value Stream Mapping is to visualize of all the sub-manufacturing activities includes the information flow and the material flow which existed along the value stream chosen of the product [5]. Value Stream Mapping reveals the significant wastes activities accumulated in the current process that contributed to the profit deterioration. The wastes or nonvalue added activities consume more manpower and money and add the important amount of leadtime without adding value to the components. Apart from that, Lean Enterprise Research Centre concluded in their research that $5 \%$ of the total activities in a manufacturing of product consist of value-added activities, up to $35 \%$ described as the Necessary but Non-value Added Activities (NNVAA) and the last 60\% clarified as the Non-Value Added Activities (NVAA) [7]. Since nonvalue-added activity (NVAA) known as the waste in the system, most manufacturers that aware of 
this issue strived to eliminate as much waste as possible [7].

\section{LITERATURE REVIEW}

The warehouse defined as the material handling station. The tasks performed in the warehouse consist of receiving the components, the storage, accumulation, order-picking, sorting, and transportation [8]. Besides that, the warehouse responsible as the distribution center for the raw materials and commonly followed by the processes of manufacturing [9]. As shown in the Figure 1, the materials are transported by the lorry and unloaded at the receiving docks. At the dock of receipt, quantities are documented, and random quality checks are performed on the delivered loads. Afterwards, the loads are organized for deportation to the storage area. Once the materials are transferred to the storage area, or when they are transferred to the expediting area, handling takes the parts into or from their location. To minimize the time expended in retrieving orders, it is suggested that items that have the highest turnover are located nearest to the shipping area. Slowmoving items would be kept at the other end of the store.

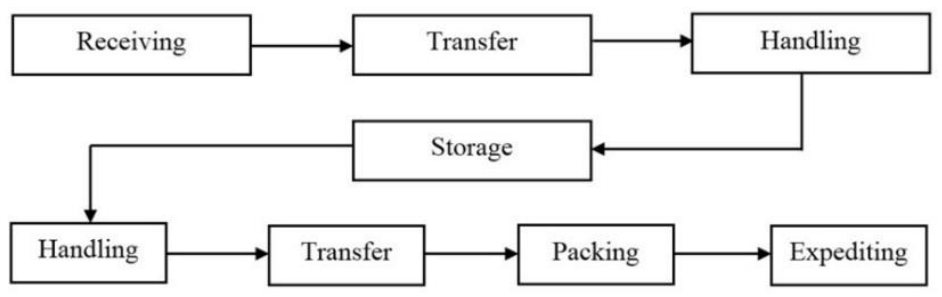

Figure 1 : Activities in the warehouse [1]

The activities in the warehouse commonly viewed as a non-valued added activities. Meanwhile, some empirical studies and developments on the supply chain logistic have given an improvement on the profit of manufacturers. The Japanese word for waste known as Muda, according to Chen et al. [10] and believed that Muda is related to every activity that does not give value added to a product. The consumption of the time and resources makes the price of the product increases. As Ohno [6] refers, the timeline between the costumer's order and the product's delivery should be studied, and the related wastes should be eliminated to reduce its duration. The original seven common wastes in an industrial environment that were originally identified by Ohno [6] consist of inventory, transportation, waiting, motion, overprocessing, overproduction, and defects. Since Lean Manufacturing is introduced, this concept has built a worldwide reputation based on outcomes related to cost reduction, production improvement and increase the customer value creation through the elimination of production wastes in several firms or companies [11]. Lean methods and techniques have changed the automotive industry to a wide range of industries and services by spreading their scope [12]. The effective way to meet the challenges of sustainable development recently proven by the lean philosophy [13].

Value Stream Mapping (VSM) can be defined as the mere process of directly observing the flows of information and materials as they now occur summarizing them visually and then envisioning a future state with much better performance [14]. VSM as an approach that is capable of tracking the wastes existing in the manufacturing processes [15]. VSM typically consist of Current State Map and Future State Map. Current State Map describe the information flow from order to raw material to finished goods. Future State Map is generated based from the Current State Map to eliminate the non-value adding steps (waste) and improving the value-adding stages of the current system. Boolean algebra is an algebra for the manipulation of objects that can take on only two values, typically true represent 1 and false represent 0 . Boolean algebra also has operations that can be performed on these objects, or variables. Two common Boolean operators are AND and OR.

\section{APPLICATION OF BOOLEAN}

Fault Tree Analysis is a well-established and well-understood technique, widely utilized for dependability assessment of an extensive variety of systems [16]. Fault Tree Analysis is deductive 
in nature meaning that the study begins with a top event (a system failure) and works in reverse from the highest point of the tree towards the leaves of the tree to decide the primary drivers of the top event. Fault tree comprises of three sorts of nodes: events, gates, and transfer symbols. Typical gates use in the fault tree consist of AND, and OR gate. The AND gate is utilized to demonstrate a true output if all of its input events are true and OR gate is used to describe a scenario when the output event occurs if at least one of the input events occur. For example, fault tree is used to analysis failure of the fire protection system. As shown in Figure 2, fire protection system can fail either one of fire detection system or fire suppression system is failed. A fire detection system can fail if both smoke detector unit and heat sensor unit fail but not by the failure of just one unit. In another side, a fire suppression system can fail if just one water sprinkler system unit or sprinkler nozzles unit fail.

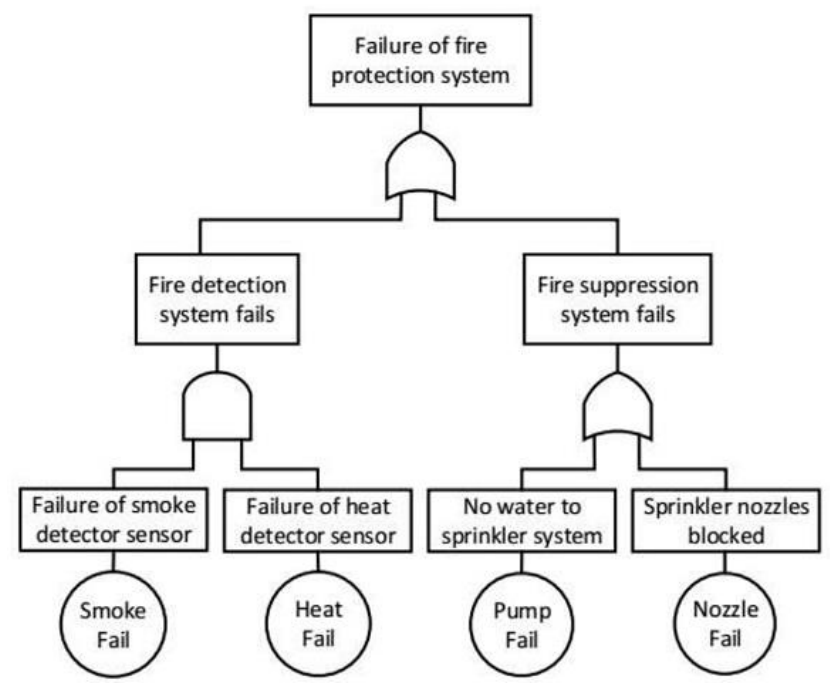

Figure 2 : Fault Tree Analysis Diagram [16]

According to Wang et al. [17], in their study, application of Boolean logic operations executed by enzymes to control electrochemical systems is presented. Indium-tin oxide (ITO) electrodes with the surface modified with the poly-4-vinyl pyridine (P4VP) brush were joined and used as switchable electrochemical systems. The switch 1 and 0 of the electrode action were accomplished by $\mathrm{pH}$ changes produced by biocatalytic reactions within sight of enzymes utilized as the incoming signals. Two logic gates working as AND/OR Boolean functions were built utilizing invertase and glucose oxidase or esterase and glucose oxidase as incoming signals, respectively.

In Computer Aided Modelling application, according to Hung \& Lai [18], a Boolean-based algorithm is presented for planar profiles, which is a typical execution for overlapping elimination in Cutter Location paths generation. The Boolean-based algorithm is applied on avoiding interference between individual raw tool-paths. Detection and implementation of Boolean operations between general planar limits are one of the most imperative issues which have been actualized in different applications. Computing the Boolean AND, OR, and NOT between two planar profiles plays a significant role in solving Computer Aided Geometric Design problems. Frequently, it is performed on computer-aided manufacturing, for example, machining tool-path generation between multiple CL (cutter location) paths.

\section{WASTE SIMPLIFICATION AND COMBINATION}

Several phases involved to simplify the wastes and create the combination that meets the minimum requirement of the warehouse shown in Figure 3. 


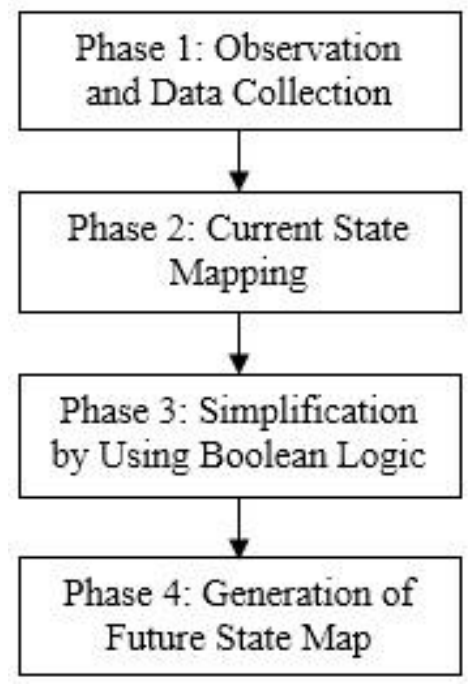

Figure 3 : Waste Identification and Elimination

\subsection{Phase 1}

Observe the activities that involved within the selected warehouse of the automotive industry. At the moment, data collection identified the current procedure in the warehouse such as Standard Operating Procedure, existing Process Flow Chart (PFC), and also a conversation with the person in charge of the warehouse is needed. All the information and necessary data are generated by the activities recorded by using a stopwatch and video recorder.

\subsection{Phase 2}

Value Stream Mapping concept is applied during this phase to obtain the current state map of the activities in the warehouse. The information and data collected from the Phase 1 are utilized to draw the current state map of the activities. The current state map consists of the mapping of the information flow, material flow, and process flow. At this phase, the wastes and non-value added accumulated in the warehouse are revealed.

\subsubsection{Illustrative Example}

Figure 4 illustrated the example of material flow in the current state map. The material Y arrived at the stations from the receiving bay and stored at each station for certain time. Assume that, the warehouse consists of 4 stations. The material $Y$ have to wait in between of stations before can be moved to the next station. After a certain period, the material $\mathrm{Y}$ will be transferred from the stations into the production line.

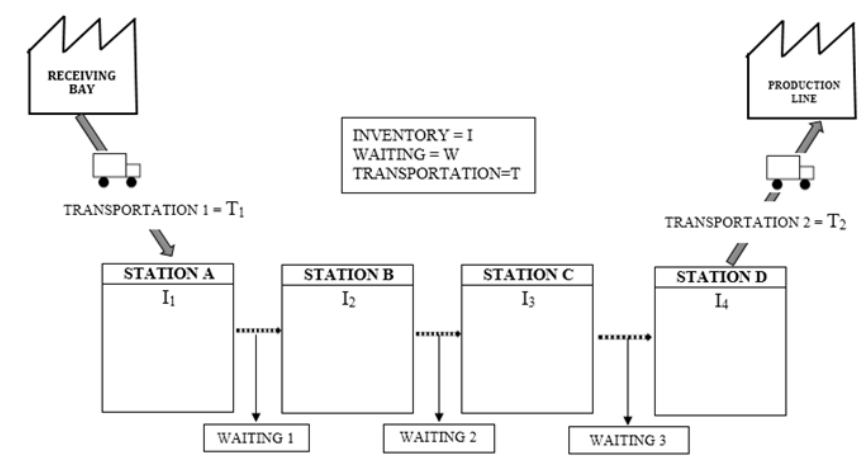

Figure 4 : Illustrative Example of Current State of VSM 
In reality, the times consumed by each station are differ based on the nature or requirements of the stations. For example, time for the material to be stored in the next station maybe longer than previous station. But, to make it easy to understand the concept of this study, we assume that, the time for each activity have a same value, where $X_{1}, X_{2}, X_{3}$ and $X_{4}$ represent the time for each inventory activities. While $\mathrm{X}_{5}, \mathrm{X}_{6}$, and $\mathrm{X}_{7}$ represent the time for each waiting activities, and finally, $X_{8}$ and $X_{9}$ represent the time for both incoming and outgoing's transportation activities. As shown in Table 1, the product of activities and time is determined as the time consumed.

Table 1: Example of Time Consumed

\begin{tabular}{|c|c|c|}
\hline Activities & Time & Time Consumed \\
\hline $\mathrm{I}_{1}$ & $X_{1}$ & $\mathrm{I}_{1} X_{1}$ \\
\hline $\mathrm{I}_{2}$ & $X_{2}$ & $\mathrm{I}_{2} X_{2}$ \\
\hline $\mathrm{I}_{3}$ & $X_{3}$ & $\mathrm{I}_{3} X_{3}$ \\
\hline $\mathrm{I}_{4}$ & $X_{4}$ & $\mathrm{I}_{4} X_{4}$ \\
\hline $\mathrm{W}_{1}$ & $X_{5}$ & $\mathrm{~W}_{1} X_{5}$ \\
\hline $\mathrm{W}_{2}$ & $X_{6}$ & $\mathrm{~W}_{2} X_{6}$ \\
\hline $\mathrm{W}_{3}$ & $X_{7}$ & $\mathrm{~W}_{3} X_{7}$ \\
\hline $\mathrm{T}_{1}$ & $X_{8}$ & $\mathrm{~T}_{1} X_{8}$ \\
\hline $\mathrm{T}_{2}$ & $\mathrm{X}_{9}$ & $\mathrm{~T}_{2} X_{9}$ \\
\hline
\end{tabular}

\subsection{Phase 3}

At this phase, the Boolean logic concept consists of, AND gate and OR gate concept is used to simplify the wastes and non-value added in the warehouse with a step-by-step approach to meet the minimum requirements of the warehouse. In the previous phase, the wastes from the warehouse can be identified by using the Current State Map and can be eliminated by the Boolean logic. Logic gate AND determined both wastes need to stay in the warehouse, and OR gate justified which wastes can be eliminated. Based on the Figure 5, Pout represent the output of all the process in the warehouse to deliver the part required by the production line. The activities involved to produce output $\mathbf{P}_{\text {out }}$ consist of $\mathbf{I}, \mathbf{W}$ and $\mathbf{T}$. Each of the activities generated by inputs, ( $\left(\mathrm{I}=\mathrm{I}_{1}, \mathrm{I}_{2}, \mathrm{I}_{3}, \mathrm{I}_{4}\right.$ ), (W $\left.=\mathrm{W}_{1}, \mathrm{~W}_{2}, \mathrm{~W}_{3}\right)$, and $\mathrm{T}=\left(\mathrm{T}_{1}, \mathrm{~T}_{2}\right)$.

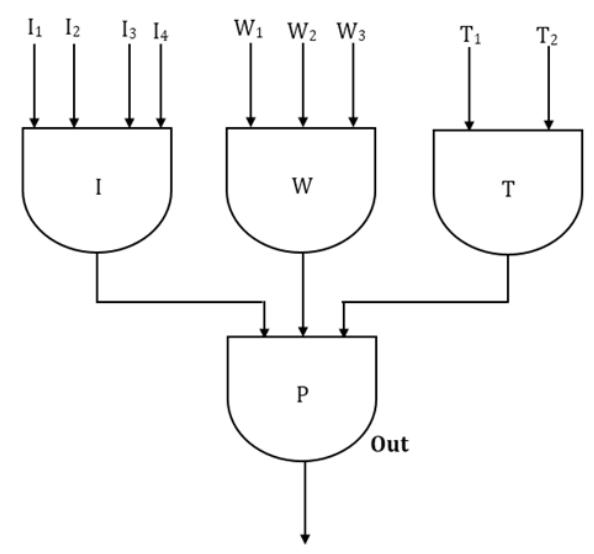


Figure 5 : Illustrative Example of Inputs and Outputs of Current Warehouse Activities

$$
\begin{aligned}
& P_{\text {OUT }}=I \cdot W \cdot T \\
& I=\left\{I_{1} X_{1} \cdot I_{2} X_{2} \cdot I_{3} X_{3} \cdot I_{4} X_{4}\right\} \\
& W=\left\{W_{1} X_{5} \cdot W_{2} X_{7} \cdot W_{3} X_{7}\right\} \\
& T=\left\{T_{1} X_{8} \cdot T_{2} X_{9}\right\}
\end{aligned}
$$

As shown in Figure 6, Logic gate OR is applied to the inventory and waiting to reduce the activities as an event occurs as long as at least one of the input events takes place. All the gates are used to eliminate the unnecessary activities and to retain the necessary for both activities required by the warehouse. Table 2 has shown the truth table of OR gates for inventory and waiting. The optimum combination can be obtained by selecting the minimum inventory activities and waiting activities according to the truth table, and for example, 1 activity represents the inventory, and 1 activity represent waiting activities.

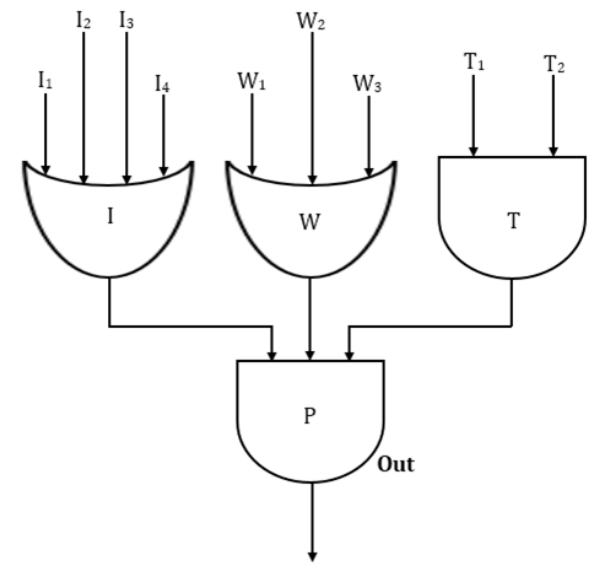

Figure 6 : Illustrative Example of Inputs and Outputs for Elimination of Wastes

Assuming that, $T_{1}$ represent as the receiving the activities of the raw material from the receiving bay, and $\mathrm{T}_{2}$ represent as the transportation of the complete part into the production line. $\mathrm{T}_{1}$ and $\mathrm{T}_{2}$ can be considered as the minimum requirement for the transportation in the warehouse. Thus, $T_{1}$ and $T_{2}$ are the transportation activities need to be retained in the warehouse. Table 2 shown the truth table as the result of our proposed method to eliminate wastes as shown in Figure 6. From the Table 2, there are 12 possibilities to minimize the wastes.

\subsection{Phase 4}

Table 2 shown the truth table as the result of our proposed method to eliminate wastes as shown in Figure 6. From the Table 2, there are 12 possibilities to minimize the wastes. When,

- $\mathrm{I}_{4}=1, \mathrm{I}_{1}=\mathrm{I}_{2}=\mathrm{I}_{3}=0$ and $\mathrm{W}_{3}=1, \mathrm{~W}_{1}=\mathrm{W}_{2}=0$

- $\mathrm{I}_{4}=1, \mathrm{I}_{1}=\mathrm{I}_{2}=\mathrm{I}_{3}=0$ and $\mathrm{W}_{2}=1, \mathrm{~W}_{1}=\mathrm{W}_{3}=0$

- $\mathrm{I}_{4}=1, \mathrm{I}_{1}=\mathrm{I}_{2}=\mathrm{I}_{3}=0$ and $\mathrm{W}_{1}=1, \mathrm{~W}_{2}=\mathrm{W}_{3}=0$

- $\mathrm{I}_{3}=1, \mathrm{I}_{1}=\mathrm{I}_{2}=\mathrm{I}_{4}=0$ and $\mathrm{W}_{3}=1, \mathrm{~W}_{1}=\mathrm{W}_{2}=0$

- $\mathrm{I}_{3}=1, \mathrm{I}_{1}=\mathrm{I}_{2}=\mathrm{I}_{4}=0$ and $\mathrm{W}_{2}=1, \mathrm{~W}_{1}=\mathrm{W}_{3}=0$

- $\mathrm{I}_{3}=1, \mathrm{I}_{1}=\mathrm{I}_{2}=\mathrm{I}_{4}=0$ and $\mathrm{W}_{1}=1, \mathrm{~W}_{2}=\mathrm{W}_{3}=0$

- $\mathrm{I}_{2}=1, \mathrm{I}_{1}=\mathrm{I}_{3}=\mathrm{I}_{4}=0$ and $\mathrm{W}_{3}=1, \mathrm{~W}_{1}=\mathrm{W}_{2}=0$ 
- $\mathrm{I}_{2}=1, \mathrm{I}_{1}=\mathrm{I}_{3}=\mathrm{I}_{4}=0$ and $\mathrm{W}_{2}=1, \mathrm{~W}_{1}=\mathrm{W}_{3}=0$

- $\mathrm{I}_{2}=1, \mathrm{I}_{1}=\mathrm{I}_{3}=\mathrm{I}_{4}=0$ and $\mathrm{W}_{1}=1, \mathrm{~W}_{2}=\mathrm{W}_{3}=0$

- $\mathrm{I}_{1}=1, \mathrm{I}_{2}=\mathrm{I}_{3}=\mathrm{I}_{4}=0$ and $\mathrm{W}_{3}=1, \mathrm{~W}_{1}=\mathrm{W}_{2}=0$

- $\mathrm{I}_{1}=1, \mathrm{I}_{2}=\mathrm{I}_{3}=\mathrm{I}_{4}=0$ and $\mathrm{W}_{2}=1, \mathrm{~W}_{1}=\mathrm{W}_{3}=0$

- $\mathrm{I}_{1}=1, \mathrm{I}_{2}=\mathrm{I}_{3}=\mathrm{I}_{4}=0$ and $\mathrm{W}_{1}=1, \mathrm{~W}_{2}=\mathrm{W}_{3}=0$.

Table 2 : Truth table of Wastes Possibilities

\begin{tabular}{|c|c|c|c|c|c|c|c|}
\hline $\mathrm{I}_{1}$ & $\mathrm{I}_{2}$ & $\mathrm{I}_{3}$ & $\mathrm{I}_{4}$ & $\mathrm{~W}_{1}$ & $\mathrm{~W}_{2}$ & $\mathrm{~W}_{3}$ & $\mathrm{P}$ \\
\hline 0 & 0 & 0 & 1 & 0 & 0 & 1 & 1 \\
\hline 0 & 0 & 0 & 1 & 0 & 1 & 0 & 1 \\
\hline 0 & 0 & 0 & 1 & 1 & 0 & 0 & 1 \\
\hline 0 & 0 & 1 & 0 & 0 & 0 & 1 & 1 \\
\hline 0 & 0 & 1 & 0 & 0 & 1 & 0 & 1 \\
\hline 0 & 0 & 1 & 0 & 1 & 0 & 0 & 1 \\
\hline 0 & 1 & 0 & 0 & 0 & 0 & 1 & 1 \\
\hline 0 & 1 & 0 & 0 & 0 & 1 & 0 & 1 \\
\hline 0 & 1 & 0 & 0 & 1 & 0 & 0 & 1 \\
\hline 1 & 0 & 0 & 0 & 0 & 0 & 1 & 1 \\
\hline 1 & 0 & 0 & 0 & 0 & 1 & 0 & 1 \\
\hline 1 & 0 & 0 & 0 & 1 & 0 & 0 & 1 \\
\hline
\end{tabular}

The future state maps can be drawn based on the probabilities that obtained from the proposed method. Figure 7 illustrated an example of a future state map constructed based on one of the possibilities. The minimum wastes can be obtained when $\mathrm{I}_{4}=1, \mathrm{I}_{1}=\mathrm{I}_{2}=\mathrm{I}_{3}=0$ and $\mathrm{W}_{3}=1$, $\mathrm{W}_{1}=\mathrm{W}_{2}=0$. Consequently, the output obtained from the previous phase used to create the new state map known as the future state map.

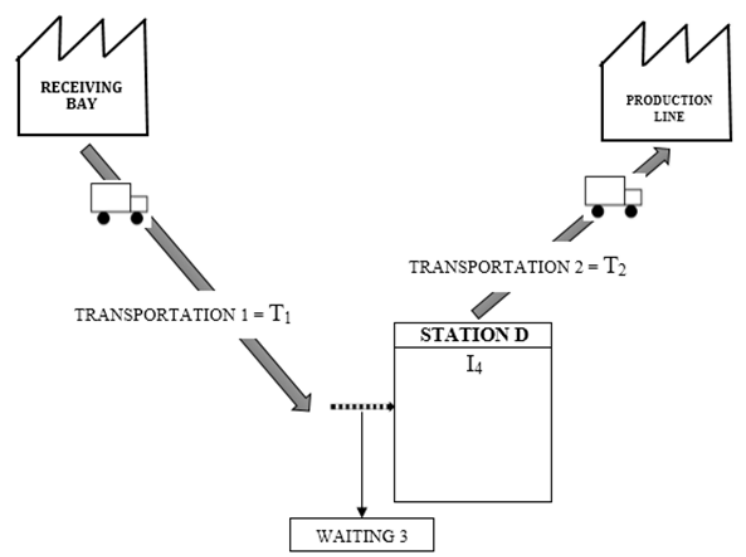

Figure 7 : Illustrative Example of a Future State Map

In this study, 7 activities are being used to create the truth table based on the Boolean diagram in Figure 5 where 2 activities are excluded since those activities are unavoidable activities in the warehouse. This will create 128 combinations of activities. From the entire combinations, 12 
possibilities are identified as the combination that can be considered as the most minimum number of wastes which consist of 4 activities.

\section{V.DISCUSSION}

The accumulation of wastes in the warehouse is one of the factors that affect the operational costs of the companies. The companies need to bear the cost to keep the existing wastes in the warehouse, and this will result to the increment of the operational costs. This situation will contribute to the higher product's prices plus the companies become less competitive in the current market.

In this study, 128 combinations were obtained from the truth table and among of them, there are 12 possibilities can be identified as the combination that contains the most minimum amount of wastes. However, the future state map still can be made based on the remaining 116 combinations if still there are any activities that cannot be removed from the warehouse. Thus, the continuous improvements are needed to simplify the wastes to produce a better future state map from time by time, and this will contribute to the sustainability for the operation of the warehouse.

\section{CONCLUSION AND FUTURE WORKS}

We would like to apply this method to the real situation and by using actual data as future progress. We believed that the input from this research could be used as a guideline in the automotive industry to identify and eliminate the wastes in the warehouse. We also would like to propose a method that can cater for the time consumed in every activity which differs from a station to another. The method will make the time at each station are equivalent to each other. Thus, the time will applicable with the proposed method that been described in this paper.

\section{AKNOWLEGDEMENT}

The authors acknowledge the research grant RDU160344 received from Universiti Malaysia Pahang.

\section{REFERENCES}

[1] Gunasekaran, A., Marri, H.B., \& Menci, F. (1999)."Improving the effectiveness of warehousing operations: a case study", Industrial Management \& Data Systems, Vol. 99 Iss 8 pp. $328-339$.

[2] Koster, R. D., Le-Duc, T., Roodbergen, K. J. (2007). "Design and control of warehouse order picking: A literature review". European Journal of Operational Research 182: 481-501

[3] Rao, K., \& Young, R. R. (1994). "Global Supply Chains: Factors Influencing Outsourcing of Logistics Functions". International Journal of Physical Distribution \& Logistics Management, Vol. 24 Iss: 6, pp.11-19

[4] William, M. F. (2001). "Lean manufacturing, Tools, techniques and how to use them". The CRC Press series on resource management. 4-19.

[5] Tapping, D., Luyster, T., and Shuker, T. (2002). "Value Stream Management, Eight Steps to Planning, Mapping, and Sustaining Lean Improvement", Productivity Press: 27-31, 113.

[6] Ohno, T. (1988). "The Toyota Production System: Beyond Large-scale Production". Portland, OR: Productivity Press.

[7] Sahoo, A., Singh, N. and Shankar, R. (2008). "Lean philosophy: implementation in a forging company." The International Journal of Advanced Manufacturing Technology 36(5): 451-462

[8] Berg, J. P. Van Den, \& Zijm, W. H. M. (1999). "Models for warehouse management: Classification and examples". International Journal of Production Economics, 59(1), 519528.https://doi.org/10.1016/S0925-5273 (98)00114-5

[9] Wutthisirisart, P., Sir, M. Y., \& Noble, J. S. (2015). "The two-warehouse material location selection problem". International Journal of Production Economics, 170, 780-789. https://doi.org/10.1016/j.ijpe.2015.07.008

[10] Chen, J. C., Li, Y., \& Shady, B. D. (2010). "From value stream mapping toward a lean/sigma 
continuous improvement process: an industrial case study". International Journal of Production Research, 48(4), 1069-1086. https://doi.org/10.1080/00207540802484911

[11] Belekoukias, I., Garza-Reyes, J. A., \& Kumar, V. (2014). "The impact of lean methods and tools on the operational performance of manufacturing organisations". International Journal of Production Research, 7543(July 2014), 1-21. https://doi.org/10.1080/00207543.2014.903348

[12] Lacerda, A. P., Xambre, A. R., \& Alvelos, H. M. (2015). "Applying Value Stream Mapping to eliminate waste: a case study of an original equipment manufacturer for the automotive industry". International Journal of Production Research.7543 (October).1-13. https://doi.org/10.1080/00207543.2015.1055349

[13] Wu, P., Low, S. P., \& Jin, X. (2013). "Identification of non-value adding (NVA) activities in precast concrete installation sites to achieve low-carbon installation". Resources, Conservation and Recycling, 81, 60-70. https://doi.org/10.1016/j.resconrec.2013.09.013

[14] Womack, J. P., \& Jones, D. T. (1996). "Beyond Toyota: How to Root Out Waste and Pursue Perfection". Harvard Business Review, 74(5), 140-158. https://doi.org/Article

[15] Ibon Serrano, L., Carlos Ochoa, L., \& Rodolfo de Castro, V. (2008). "An evaluation of the value stream mapping tool". Business Process Management Journal, 14(1), 39-52. https://doi.org/10.1108/14637150810849391

[16] Kabir, S. (2017). "An overview of Fault Tree Analysis and its application in model based dependability analysis". Expert Systems with Applications, 77, 114-135. https://doi.org/10.1016/j.eswa.2017.01.058

[17] Wang, X., Zhou, J., Tam, T. K., Katz, E., \& Pita, M. (2009). "Switchable electrode controlled by Boolean logic gates using enzymes as input signals". Bioelectrochemistry, 77(1), 69-73. https://doi.org/10.1016/j.bioelechem.2009.06.012

[18] Hung, J., \& Lai, Y. (2012). "Boolean-based operation on overlapping CL paths for 3D models". International Journal of Production Research, 50(2), 379-392. https://doi.org/10.1080/00207543.2010.5377 